\title{
Impact of aerosol hygroscopic growth on retrieving aerosol extinction coefficient profiles from elastic-backscatter lidar signals
}

\author{
Gang Zhao ${ }^{1}$, Chunsheng Zhao ${ }^{1}$, Ye Kuang ${ }^{1}$, Jiangchuan Tao ${ }^{1}$, Wangshu $\operatorname{Tan}^{1}$, Yuxuan Bian ${ }^{2}$, Jing Li $^{1}$, and \\ Chengcai $\mathbf{L i}^{1}$ \\ ${ }^{1}$ Department of Atmospheric and Oceanic Sciences, School of Physics, Peking University, Beijing, China \\ ${ }^{2}$ State Key Laboratory of Severe Weather, Chinese Academy of Meteorological Sciences, Beijing, 100081, China \\ Correspondence to: Chunsheng Zhao (zcs@pku.edu.cn)
}

Received: 15 March 2017 - Discussion started: 13 April 2017

Revised: 4 September 2017 - Accepted: 8 September 2017 - Published: 12 October 2017

\begin{abstract}
Light detection and ranging (lidar) measurements have been widely used to profile the ambient aerosol extinction coefficient $\left(\sigma_{\mathrm{ext}}\right)$. The particle extinction-to-backscatter ratio (lidar ratio, LR), which strongly depends on the aerosol dry particle number size distribution (PNSD) and aerosol hygroscopicity, is introduced to retrieve the $\sigma_{\text {ext }}$ profile from elastic-backscatter lidar signals. Conventionally, a constant column-integrated LR that is estimated from aerosol optical depth is used by the retrieving algorithms. In this paper, the influences of aerosol PNSD, aerosol hygroscopic growth and relative humidity $(\mathrm{RH})$ profiles on the variation in LR are investigated based on the datasets from field measurements in the North China Plain (NCP). Results show that LR has an enhancement factor of 2.2 when RH reaches $92 \%$. Simulation results indicate that both the magnitude and vertical structures of the $\sigma_{\text {ext }}$ profiles by using the column-related LR method are significantly biased from the original $\sigma_{\text {ext }}$ profile. The relative bias, which is mainly influenced by $\mathrm{RH}$ and PNSD, can reach up to $40 \%$ when RH at the top of the mixed layer is above $90 \%$. A new algorithm for retrieving $\sigma_{\text {ext }}$ profiles and a new scheme of LR enhancement factor by RH in the NCP are proposed in this study. The relative bias between the $\sigma_{\text {ext }}$ profile retrieved with this new algorithm and the ideal true value is reduced to below $13 \%$.
\end{abstract}

\section{Introduction}

Atmospheric aerosols can directly scatter and absorb solar radiation, thus exerting significant impacts on the atmospheric environment and climate change. Vertical distribu- tions of aerosol particles are crucial for studying the roles of atmospheric aerosols in the radiation balance of the Earthatmosphere system (Kuang et al., 2016), air pollution transportation (Gasteiger et al., 2017) and boundary layer processes. However, there remain many problems when determining the spatial and temporal distributions of aerosols because of their highly variable properties (Anderson and Anderson, 2003; Andreae and Crutzen, 1997) and complex sources. As a result, our knowledge of the vertical distributions of aerosols is still very limited.

Light detection and ranging (lidar) instruments are useful remote-sensing tools to monitor profiles of aerosol optical properties. This kind of instrument involves a pulsed laser beam, which can be used to detect the backscatter signals from aerosols and air molecules in the atmosphere (Klett, 1981). Elastic-backscatter lidar is one of the most frequently used instruments (He et al., 2006; Pietruczuk and Podgórski, 2009). However, there are some limitations when deriving the aerosol extinction coefficient $\left(\sigma_{\text {ext }}\right)$ and aerosol backscattering coefficient $\left(\beta_{\text {sca }}\right)$ from elastic-backscatter lidar signals. Many efforts have been carried out to retrieve the $\sigma_{\text {ext }}$ profiles from lidar signals (Klett, 1981, 1985). Particle extinction-tobackscatter ratio, which is usually termed as the lidar ratio (LR), is required when retrieving $\sigma_{\text {ext }}$ profiles (Fernald, 1984; Fernald et al., 1972). LR can be derived directly using Raman lidar (Pappalardo et al., 2004b) and high-spectral-resolutionlidar (She et al., 1992; Shipley et al., 1983; Sroga et al., 1983) measurements. Raman lidar has low signal to noise ratios (SNR) during the day, which may lead to significant bias and uncertainties in retrieving lidar signals. High spectral resolution lidar have high technical requirements and are 
expensive. Ansmann et al. (2002) demonstrated that the profile of the LR could be retrieved from Raman lidar and this LR profile can be used to retrieve $\sigma_{\text {ext }}$ profiles from high SNR elastic-backscattering lidar data. However, there exist many cases when elastic-backscatter lidar is used without concurrently measured LR profiles.

Sun photometer, radiometer and elastic-backscatter lidar data are usually used simultaneously to retrieve $\sigma_{\text {ext }}$ profiles (Chaikovsky et al., 2016; He et al., 2006). In these studies, $\sigma_{\text {ext }}$ profiles could be retrieved from elastic-backscatter lidar signals by using a constant column-related LR, which is constrained by measurements of aerosol optical depth (AOD) from a sun photometer. However, many factors such as aerosol particle number size distribution (PNSD), aerosol refractive index, aerosol hygroscopicity and ambient relative humidity (RH) have large influences on LR. It is found that the ratio of $\sigma_{\text {ext }}$ to $\beta_{\text {sca }}$ grows linearly but slowly as RH increases when RH is lower than $80 \%$ (Ackermann, 1998; Anderson et al., 2000; Ferrare et al., 2001). Further research found that LR is likely to change significantly due to the substantial variation in RH in the mixed layer (Ferrare et al., 1998). Small errors from the initial conditions may lead to a large bias of retrieved $\sigma_{\text {ext }}$ profiles (Sušnik et al., 2014). It is likely that using a constant LR profile instead of a variable LR profile to retrieve elastic-backscatter lidar data may result in a significant bias of retrieved $\sigma_{\text {ext }}$ profiles. The sounding profiles show that RH is highly variable and frequently exceeding $80 \%$ in the mixed layer in the North China Plain (NCP; Kuang et al., 2016), which is one of the most polluted areas around the world (Ma et al., 2011; Xu et al., 2011). Accordingly, it is interesting to know by how much $\sigma_{\text {ext }}$ profiles retrieved from elastic-backscatter lidar signals will deviate if a constant column-related LR profile is used in the NCP. Few studies have been performed to assess the bias of using a constant LR profile. This work comprehensively studies the possible bias by employing a large dataset of field measurements.

To account for aerosol hygroscopic growth, $\kappa$-Köhler theory (Petters and Kreidenweis, 2007) is widely used, in which the chemical composition-dependent variables are merged into a single parameter $\kappa$. The $\kappa$-Köhler equation is expressed as

$$
\frac{\mathrm{RH}}{100}=\frac{\mathrm{GF}^{3}-1}{\mathrm{GF}^{3}-(1-\kappa)} \times \exp \left(\frac{4 \sigma_{s / a} M_{\mathrm{water}}}{R \times T \times D_{\mathrm{d}} \times \mathrm{GF} \times \rho_{\mathrm{w}}}\right),
$$

where $D_{\mathrm{d}}$ is the aerosol dry diameter, GF is the aerosol growth factor, which is defined as the ratio of the aerosol diameter under the given $\mathrm{RH}$ and dry conditions $\left(D_{\mathrm{RH}} / D_{\mathrm{d}}\right), T$ is the temperature, $\sigma_{s / a}$ is the surface tension of the solution, $M_{\text {water }}$ is the molecular weight of water, $R$ is the universal gas constant and $\rho_{\mathrm{w}}$ is the density of water.

This article is structured in the following way. Section 2 shows all of the data used in this study. Section 3 gives the methodology of this research. Mie theory (Bohren and

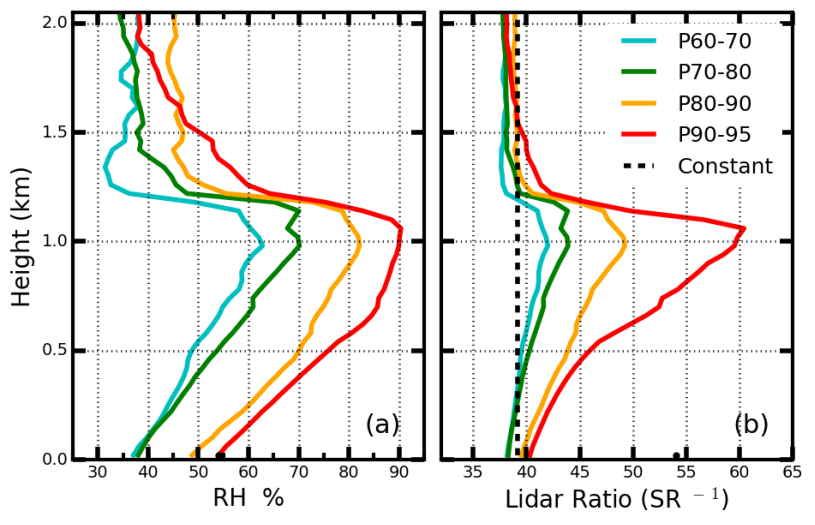

Figure 1. (a) Four kinds of RH profiles P60-70, P70-80, P80-90, and P90-95; (b) calculated LR profiles from the corresponding RH profiles of (a). The dashed black line is one of the constant LR profiles that are used to retrieve the MPL signals.

Huffman, 2007) and $\kappa$-Köhler theory (Petters and Kreidenweis, 2007) are used to study the influences of aerosol hygroscopic growth on LR. By calculating the LR at different $\mathrm{RH}$, it is found that the RH-related LR profiles are significantly different from the constant LR profile as shown in Fig. $1 \mathrm{~b}$. We simulate the bias of the retrieved $\sigma_{\text {ext }}$ profiles by using the AOD-related constant LR profiles in three steps. Firstly, the vertical distributions of the aerosol are parameterized and the corresponding aerosol $\sigma_{\text {ext }}$ and $\beta_{\text {sca }}$ profiles are calculated in Sect. 3.2. Secondly, we calculate the theoretical signals received by the elastic-backscatter lidar in Sect. 3.3 by using the $\sigma_{\text {ext }}$ and $\beta_{\text {sca }}$ profiles of the first step. Finally, we retrieve the $\sigma_{\text {ext }}$ profiles from the lidar signals of Sect. 3.3 by using the column-related lidar ratio profiles, in which the method is detailed in Sect. 3.4.1. Then the retrieved $\sigma_{\text {ext }}$ profiles are compared with the parameterized $\sigma_{\text {ext }}$ profiles. In Sect. 3.4.2, we propose a new method of retrieving the $\sigma_{\text {ext }}$ profiles, which can account for the variations in LR with RH. Results and discussions are shown in Sect. 4. Section 4.2 shows the bias of retrieved $\sigma_{\text {ext }}$ profiles by using a column-related LR profile method. Section 4.2.1 gives the possible bias of the retrieved $\sigma_{\text {ext }}$ profiles and Sect. 4.2.2 shows the sensitivity of the bias under different AOD, different aerosol PNSD, different RH profiles and different aerosol hygroscopicity conditions. In Sect. 4.4, real-time field measurements from a micro-pulsed lidar (MPL) are used to validate the feasibility of our new proposed method. The conclusions of this research are summarized in Sect. 5.

\section{Data}

\subsection{Datasets of aerosol properties}

During the periods of the Haze in China (HaChi) campaign, the physical and chemical properties of aerosol par- 
ticles were measured at the Wuqing meteorological station $\left(39^{\circ} 23^{\prime} \mathrm{N}, 117^{\circ} 0^{\prime} \mathrm{E} ; 7.4 \mathrm{ma}\right.$ a.s.1.). Wuqing is located between two megacities (Beijing and Tianjin) of the NCP, and can represent the pollution conditions of the NCP (Xu et al., 2011).

This study uses the measured datasets of PNSD, black carbon (BC) mass concentrations (Ma et al., 2012) and aerosol hygroscopicity (Chen et al., 2014; Liu et al., 2014) during the field campaign. The sampled aerosol particles are selected to have an aerodynamic diameter of less than $10 \mu \mathrm{m}$ by an impactor at the initial inlet. These particles are carefully dried to below $40 \% \mathrm{RH}$ and then led to the corresponding instruments. The aerosol PNSDs with particle diameters in the range from $10 \mathrm{~nm}$ to $10 \mu \mathrm{m}$ are measured by jointly using a differential mobility particle sizer (TDMPS, Leibniz Institute for Tropospheric Research, Germany; Birmili et al., 1999) and an aerodynamic particle sizer (APS, TSI Inc., model 3321) with a temporal resolution of $5 \mathrm{~min}$. The BC mass concentrations are measured by a multi-angle absorption photometer (MAAP, model 5012, Thermo, Inc., Waltham, MA, USA). The aerosol hygroscopicity is measured by using the humidity tandem differential mobility analyzer (HTDMA), which measures the aerosol GF as a function of RH at different diameters. The aerosol hygroscopicity parameter $\kappa$ can be directly derived from measurements of the HTDMA by applying Eq. (1).

\subsection{RH profiles}

The intensive GTS1 observation (Bian et al., 2011) at the meteorological bureau of Beijing $\left(39^{\circ} 48^{\prime} \mathrm{N}, 116^{\circ} 28^{\prime} \mathrm{E}\right)$ were carried out from July to September 2008. With a resolution of $10 \mathrm{~m}$ in the vertical direction, the radiosonde data include profiles of temperature, pressure and RH. During the intensive observation period, balloon soundings were performed four times a day. The water vapor mixing ratio is almost constant in the mixed layer due to extensive turbulent mixing, and decreases rapidly above the mixed layer. $\mathrm{RH}$ profiles that exhibit well-mixed vertical structures were selected and studied. $\mathrm{RH}$ profiles are classified into four typical groups based on the maximum RH ranges: 60-70, 70-80, 80-90 and 90$95 \%$ (Kuang et al., 2016). These four kinds of typical wellmixed RH profiles are labeled as P60-70, P70-80, P80-90 and P90-95 respectively. These four kinds of RH profiles, which are shown in Fig. 1a, are used to conduct the sensitivity studies in this article.

\subsection{MPL signals}

A single wavelength polarization diversity elastic lidar system is installed on the roof of the physics building in Peking University. This instrument is a MPL manufactured by Sigma Space, using a Nd:YVO $532 \mathrm{~nm}$ pulsed DC10H-532SS laser source, with a pulse duration of $10.3 \mathrm{~ns}$, energy of $6-8 \mu \mathrm{J}$ and a repetition of $2500 \mathrm{~Hz}$. It collects elastically backscattered signals from the atmosphere by separately detecting its par- allel and cross polarization components with respect to the polarization of the laser. We also used the concurrently measured AOD data from the AERONET Beijing PKU station, which is located at the same place as the Lidar.

\section{Methodology}

\subsection{Influences of aerosol hygroscopic growth on LR}

\subsubsection{Calculation of the LR values under different RH conditions}

In this paper, the Mie model (Bohren and Huffman, 2007) is used to study the influence of RH on LR. When running the Mie model, aerosol PNSD, aerosol complex refractive index, black carbon mixing state and black carbon mass concentrations are essential. The results of the Mie model contain information about $\sigma_{\text {ext }}$ and $\beta_{\text {sca }}$, which can be used to calculate the $\mathrm{LR}$ directly, with $\mathrm{LR}=\frac{\sigma_{\mathrm{ext}}}{\beta_{\mathrm{sca}}}$.

When exposed to ambient environment, the aerosols grow. To account for this, we use the size-resolved hygroscopicity parameter $\kappa$, which is derived from the measurements of the HTDMA (Chen et al., 2012; Liu et al., 2011). This size-resolved $\kappa$ is shown in Fig. S1. The mean distribution of the size-resolved $\kappa$ during the Hachi Campaign is used. With this, the aerosol GF for different $D_{\mathrm{d}}$ and RH can be calculated by applying Eq. (1).

Mixing states of $\mathrm{BC}$ come from the measurements during the Hachi Campaign. In previous work, BC mixing states during the Hachi campaign were presented as both coreshell mixed and externally mixed (Ma et al., 2012). Ma et al. (2012) provides the ratio of BC mass concentration under an externally mixed state, $M_{\text {ext_BC}}$, to total BC mass concentration, $M_{\mathrm{BC}}$, as follows:

$r_{\text {ext } \_ \text {BC }}=\frac{M_{\text {ext_BC }}}{M_{\mathrm{BC}}}$.

The mean value of $r_{\text {ext_BC }}=0.51$ (Ma et al., 2012) is used as a representation of the mixing state in this study. The sizeresolved distribution of $\mathrm{BC}$ mass concentration is the same as that used by Ma et al. (2012a).

The refractive index $(\widetilde{m})$, accounting for the water content in the particle, is derived as a volume mixture between the dry aerosol and water (Wex et al., 2002) as follows:

$\widetilde{m}=f_{\mathrm{v}, \text { dry }} \widetilde{m}_{\text {aero, dry }}+\left(1-f_{\mathrm{v}, \text { dry }}\right) \widetilde{m}_{\mathrm{water}}$,

where $f_{\mathrm{v}, \text { dry }}$ is the ratio of the dry aerosol volume to total aerosol volume at a given RH condition; $\widetilde{m}_{\text {aero, dry }}$ is the refractive index of dry ambient aerosols and $\widetilde{m}_{\text {water }}$ is the refractive index of water. The refractive indices of $\mathrm{BC}$, nonlight-absorbing aerosols and water, which are used in this study, are $1.8+0.54 i$ (Kuang et al., 2015), $1.53+10^{-7} i$ (Wex et al., 2002) and $1.33+10^{-7} i$, respectively. 

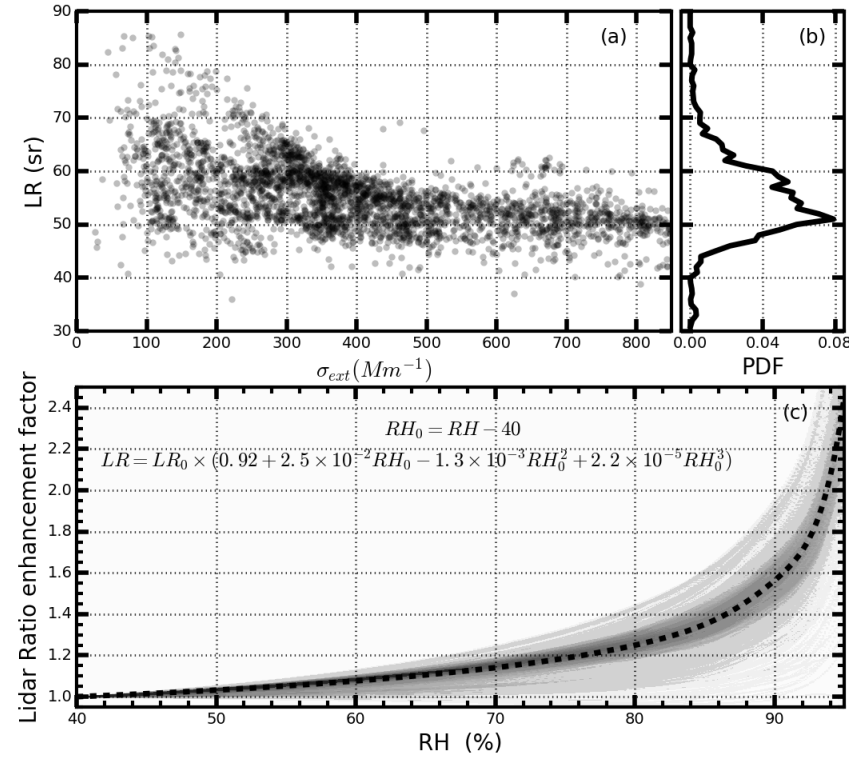

Figure 2. LR distribution and LR enhancement factor during the Hachi campaign. (a) LR distribution under different polluted conditions. (b) Probability distribution function (PDF) of the LR. (c) Enhancement factor of the LR. The dashed line is the mean fit LR enhancement factor.

To sum up, we can calculate the LR of a PNSD under the given RH condition by using the Mie scattering model. For a dry aerosol PNSD, the corresponding aerosol PNSD at a given RH can be calculated by applying the mean distribution of size-resolved $\kappa$ and Eq. (1). The aerosol refractive index can be determined from Eq. (3) also. With this information, the LR can be calculated. For each aerosol PNSD, we change the RH from 40 to $95 \%$ to calculate the LR values at different RH. Finally, the LR values of different measured aerosol PNSDs at different RH are calculated by using the same method.

\subsubsection{Parameterizing the variation in $L R$ with $R H$}

When the LR values under different RH are statistically studied, we find that the LR can be enhanced when the RH increases, which will be discussed in detail in Sect. 4.1.1 and shown in Fig. 2.

The LR enhancement factor is introduced to describe the influence of aerosol hygroscopic growth on LR at different RH. It is defined as the ratio of LR at a given RH to LR at the condition of $\mathrm{RH}<40 \%$. We give the statistical mean relationships between the LR enhancement factor and RH. The LR enhancement factor can account for the increase in LR with RH and the parameterized LR enhancement factor is further used in our proposed method to retrieve the $\sigma_{\text {ext }}$ profiles.

\subsection{LR profiles and $\sigma_{\text {ext }}$ profiles}

Liu et al. (2009) studied vertical profiles of aerosol total number concentration $\left(\mathrm{N}_{a}\right)$ with aircraft measurements, and derived a parameterized vertical distribution. In this scheme, $\mathrm{N}_{a}$ is constant in the mixed layer with a transition layer where it linearly decreases and an exponential decrease in $\mathrm{N}_{a}$ above the transition layer. The same parameterized scheme proposed by Liu et al. (2009) is adopted by this study. Both the study of Liu et al. (2009) and Ferrero et al. (2010) manifest that the dry aerosol PNSD in the mixed layer varies little. The shape of the dry aerosol PNSD is assumed constant with height, which means that aerosol PNSD at different heights divided by $\mathrm{N}_{a}$ give the same normalized PNSD.

As for the BC vertical distribution, Ferrero et al. (2011) and Ran et al. (2016) demonstrate that BC mass concentration in the mixed layer remains relatively constant and decreases sharply above the mixed layer. According to this, the parameterization scheme of the $\mathrm{BC}$ vertical distribution is assumed to be the same as that of aerosol. The shape of the size-resolved BC mass concentration distribution is also assumed to be the same as that at the surface.

LR profiles and $\sigma_{\text {ext }}$ profiles can be calculated by Mie theory under these assumptions. Details of computing $\sigma_{\text {ext }}$ profiles can be found in Kuang et al. (2015). The calculated LR profiles and $\sigma_{\text {ext }}$ profiles are used in the following study to provide the theoretical elastic-backscatter signals.

\subsection{Simulated elastic-backscatter lidar signals}

The intensity of signals received by elastic-backscatter lidar depends on the optical properties of objects and the distance between scattering objects and the receiving system. It can be typically described by the following formula:

$P(R)=C \times P_{0} \times \frac{\beta(R)}{R^{2}} \times \mathrm{e}^{\int_{0}^{R}-2 \times \sigma(R) \times \mathrm{d} r}$

In Eq. (4), $P_{0}$ is the intensity of the laser pulse, $r$ is the spatial distance between scattering objects and the receiving system, $C$ is a correction factor determined by the status of the elastic-backscatter lidar machine itself, $\beta(R)$ refers to the sum of aerosol backscattering coefficient $\left(\beta_{\mathrm{sca}}\right)$ and air molecule backscattering coefficient ( $\beta_{\text {sca, mole }}$ ) at distance $R$, $\sigma(R)$ denotes the sum of $\sigma_{\text {ext }}$ and air molecule's extinction coefficient $\left(\sigma_{\text {ext, mole }}\right)$. $\beta_{\text {sca, mole }}$ and $\sigma_{\text {ext, mole }}$ can be calculated by using Rayleigh scattering theory when the temperature and pressure are available.

In this study, we can theoretically get the intensities of elastic-backscatter lidar signals and the AOD from each given $\sigma_{\text {ext }}$ and $\beta_{\text {sca }}$ profiles with the assumption that $C=1$. Retrieving elastic-backscatter lidar signals can result in exactly the same $\sigma_{\text {ext }}$ profile as the original one when the profile of LR is available. However, using a constant columnrelated LR profile to retrieve elastic-backscatter lidar signals will cause the retrieved $\sigma_{\text {ext }}$ profile to deviate from the initial $\sigma_{\text {ext }}$ profile. 


\subsection{Retrieving $\sigma_{\text {ext }}$ profiles from elastic-backscatter lidar signals}

\subsubsection{Retrieving $\sigma_{\text {ext }}$ profiles by using the constant column-related LR profile method}

Traditionally, the AOD from a sun photometer and the elastic-backscatter lidar signals are combined to retrieve the $\sigma_{\text {ext }}$ profiles. Additional information is needed to get the mathematical results of Eq. (4) because there are two unknown parameters $\left(\beta_{\text {sca }}\right.$ and $\left.\sigma_{\text {ext }}\right)$. The commonly used method of solving this formula is to assume a constant value of column-related LR and then the profiles of $\sigma_{\text {ext }}$ and $\beta_{\text {ext }}$ can be retrieved (Fernald, 1984; Klett, 1985). Different values of column-related LR can lead to different $\sigma_{\text {ext }}$ profiles and different AODs. A constant column-related LR can be constrained if the sun photometer is concurrently measuring the AOD (He et al., 2006; Pietruczuk and Podgorski, 2009). Thus, the $\sigma_{\text {ext }}$ profile can be retrieved by using the columnrelated constant LR profile.

\subsubsection{Retrieving $\sigma_{\text {ext }}$ profiles accounting for aerosol hygroscopic growth}

A new method of retrieving $\sigma_{\text {ext }}$ profiles from elasticbackscatter lidar signals is proposed, in which the variation of LR with RH can be taken into consideration. This new method requires the measured elastic-backscatter lidar signals, measured AOD data and RH profiles.

A schematic diagram of this method is shown in Fig. 3 . A parameterized LR profile is used to retrieve $\sigma_{\text {ext }}$ profiles instead of an AOD-constrained constant LR profile. Firstly, the LR enhancement factors are statistically studied and parameterized under different polluted conditions. The results of the mean parameterized LR enhancement factor, which is detailed in Sect. 4.1.1, are used in this study. The LR profile can be calculated by using the RH profile, a LR for dry aerosol and the equations of the LR enhancement factor. The $\sigma_{\text {ext }}$ profile can be retrieved with a combination of the LR profile and Eq. (4). The dry state LR value can be constrained by comparing the integrated AOD value of the retrieved $\sigma_{\text {ext }}$ profile to the concurrently measured AOD value. The LR profile is determined and the $\sigma_{\text {ext }}$ profile can be retrieved with the constrained dry state LR.

\section{Results and discussion}

\subsection{LR properties}

\subsubsection{Variation in $\mathrm{LR}$ with $\mathrm{RH}$}

During the field campaign of Hachi, 3540 different aerosol PNSDs were measured. These aerosol PNSDs can be used as a good representative dataset for the continental aerosol. LR is calculated by using different aerosol PNSD and RH values between 30 and $95 \%$.

Relationships between the dry state LR and concurrently measured $\sigma_{\text {ext }}$ (sum of the aerosol scattering and absorption) are shown in Fig. 2a. It shows that LR can vary across a wide range from 30 to $90 \mathrm{sr}$, which is consistent with the literature values of continental aerosols (Ansmann et al., 2001; Pappalardo et al., 2004a). This also indicates that calculating the LR by using Mie theory is feasible. Figure $2 b$ gives the probability distribution function of the LR. Most of the LR lies in the range between between 45 and $65 \mathrm{sr}$.

By calculating the LR values under different $\mathrm{RH}$, we find that the LR tends to increase with RH. The relationship between the LR enhancement factor and RH is given in Fig. 2c. The LR enhancement factor has a mean value lower than 1.2 when the RH is lower than $70 \%$. LR increases linearly with $\mathrm{RH}$ when RH is lower than $80 \%$. However, LR can be enhanced by a factor of 2.2 when the RH reaches $92 \%$ with mean hygroscopicity of aerosol.

Mean values of LR enhancement factor are parameterized as shown below:

$$
\begin{aligned}
& \mathrm{RH}_{0}=\mathrm{RH}-40, \\
& \mathrm{LR}=\mathrm{LR}_{\text {dry }} \times\left(0.92+2.5 \times 10^{-2} \mathrm{RH}_{0}\right. \\
& \left.-1.3 \times 10^{-3} \mathrm{RH}_{0}^{2}+2.2 \times 10^{-5} \mathrm{RH}_{0}^{3} .\right)
\end{aligned}
$$

This parameterization equation can be used as a representation of the mean effect of continental aerosol hygroscopicity on LR.

The increase in LR with RH has been studied before. Ackermann (1998) calculated the relationships of LR with RH by using the lognormal distribution of aerosols as the input of Mie scattering theory and found that the LR increases with RH for continental aerosols. However, Ackermann (1998) shows that the LR does not show the same properties for maritime aerosols or desert aerosols.

We theoretically analyze the reasons for the behavior of LR by using the Mie scattering model and the mean aerosol PNSD of the Hachi campaign. By definition, LR is the ratio of $\sigma_{\text {ext }}$ to $\beta_{\text {sca. }} \beta_{\text {sca }}$ can be written as $\beta_{\text {sca }}=\frac{\sigma_{\text {ext }} \times \operatorname{SSA} \times \operatorname{PF}(180)}{4 \times \pi}$, where SSA is single scattering albedo, which is defined as the ratio of extinction coefficient and scattering coefficient; $\mathrm{PF}(180)$ is the aerosol scattering phase function at the scattering angle of $180^{\circ}$. Thus, $\mathrm{LR}=\frac{\sigma_{\text {ext }} \times 4 \times \pi}{\sigma_{\text {ext }} \times \operatorname{SSA} \times \operatorname{PF}(180)}=$ $\frac{4 \times \pi}{5 S A \times P F(180)}$. We use the mean aerosol PNSD as the input of the Mie scattering model and calculate the aerosol phase function and SSA values at different RH. When particles grow, there tends to be larger portion of forward scattering and $\mathrm{PF}(180)$ is smaller, which is shown in Fig. S2. The $\mathrm{PF}(180)$ decreases by $40 \%$ from 0.27 to 0.16 . At the same time, the SSA increases $5 \%$ from 0.93 to 0.97 as shown in Fig. S3. Thus, the LR increases with the increase in RH. 


\subsubsection{LR ratio profiles}

Four different types of RH profiles and LR profiles are shown in Fig. 1. In Fig. 1a, RH values increase with height in the mixed layer and decrease with height above the mixed layer. This is a synthetic result of temperature and water content distributions in the vertical direction. In the summer afternoon, water vapor is well mixed within the mixed layer and decreases sharply above it. P60-70 can represent the relatively dry environmental conditions. Statistical results show that P80-90 is most likely to be observed in the environment. P90-95 is a very moist environment condition and its frequency of being observed is second to that of the P80-90 type.

Profiles of LR corresponding to RH profiles of Fig. 1a are shown in Fig. 1b. For each type of LR profile, LR increases with height in the mixed layer due to the increase in RH. At the ground, the mean values of LR for each RH profiles are $38.19,38.28,39.53$ and $40.33 \mathrm{sr}$, with a SD of $6.20,6.22$, 6.42 and 6.45 respectively. LR changes little from $38 \mathrm{sr}$ at the ground to $42 \mathrm{sr}$ at the top of the mixed layer when the ambient RH is low for the RH profile of P60-70. However, LR grows with a mean value from $40 \mathrm{sr}$ to $60 \mathrm{sr}$ with a relative difference of $50 \%$ when the $\mathrm{RH}$ is high for the $\mathrm{RH}$ profile of P90-95. With such a high variation in LR with RH, the retrieved $\sigma_{\text {ext }}$ profiles might be very different when using a constant LR profile instead of a variable one.

The black dashed line in Fig. 1b is one of the constant column-related LR profiles that are used as an input to retrieve $\sigma_{\text {ext }}$ profiles related to the RH profile P70-80. The constant LR has a higher value at the ground and a lower value at the top of the mixed layer when compared with the calculated variable LR profiles.

During the Hachi Campaign, LR values that are calculated by using Mie theory can change from 30 to $55 \mathrm{sr}$ within $12 \mathrm{~h}$ at the ground (about $87 \%$ of initial value). With a high variation in LR over time, the LR profile should be updated in time to get an accurately retrieved $\sigma_{\text {ext }}$ profile. Using only one measurement of the LR profile to retrieve the $\sigma_{\text {ext }}$ profiles may lead to a great bias of retrieved results (Rosati et al., 2016).

\subsection{Bias of retrieved $\sigma_{\text {ext }}$ profiles}

With the parameterized $\sigma_{\text {ext }}$ profiles by using the method of Sect. 3.2, we can theoretically get the AOD and the elasticbackscatter lidar signals. Then the AOD and the elasticbackscatter lidar signals can be used to constrain a columnrelated constant LR profile and to retrieve $\sigma_{\text {ext }}$ profiles. Finally, the retrieved $\sigma_{\text {ext }}$ profiles are compared with the parameterized $\sigma_{\text {ext }}$ profiles and the differences are statistically studied.

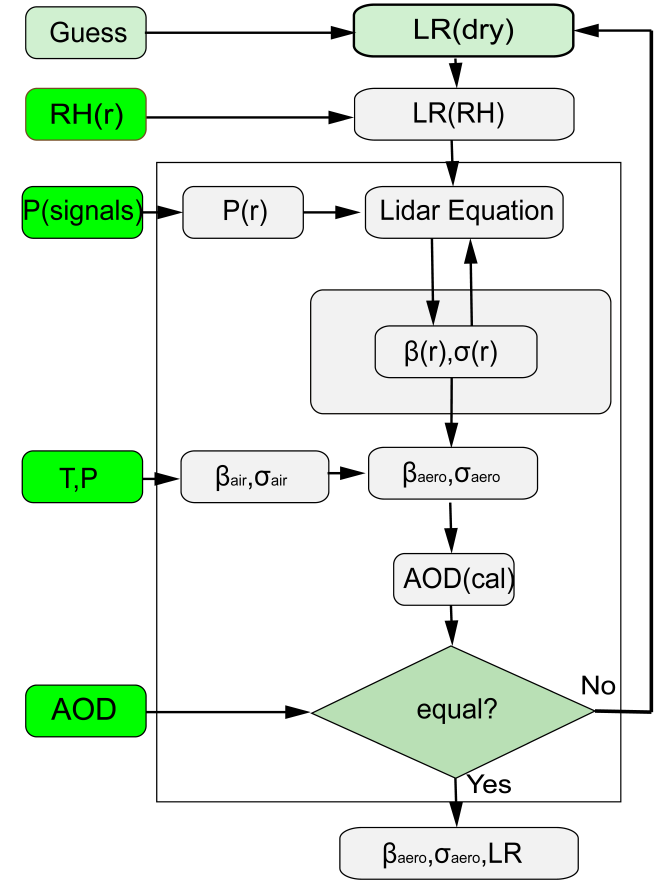

Figure 3. Schematic diagram of retrieving the $\sigma_{\text {ext }}$ profile. The input variables are displayed with a green background.

\subsubsection{Retrieved $\sigma_{\text {ext }}$ profiles vs. original $\sigma_{\text {ext }}$ profiles}

Figure 4 provides an example of the retrieved $\sigma_{\text {ext }}$ profile by using the variable LR profile method and that by using the constant LR profile method from simulated lidar signals. These two kinds of profiles can also be described as a given parameterized $\sigma_{\text {ext }}$ profile and a retrieved $\sigma_{\text {ext }}$ profile from the constant LR profile. In Fig. $4 \mathrm{a}$, the retrieved $\sigma_{\text {ext }}$ profile by using the variable LR profile method is demonstrated by a solid line. The dashed line shows the retrieved $\sigma_{\text {ext }}$ profile by using a constant column-related LR method. Figure $4 \mathrm{~b}$ shows the relative bias of the two retrieved $\sigma_{\text {ext }}$ profiles at each height. Figure $4 \mathrm{c}$ and $\mathrm{d}$ are almost the same as Fig. 4a and b, respectively, except that the results of Fig. $4 a$ and $b$ come from the RH profile of P60-70 while those of Fig. 4c and d come from the RH profile of P90-95.

It is shown in Fig. 4a that the retrieved $\sigma_{\text {ext }}$ by using a variable $L R$ profile method increases with height at a rate of $92.25\left(\mathrm{M} \mathrm{m}^{-1} \mathrm{~km}^{-1}\right)$ in the mixed layer, which is consistent with the aerosol loading and RH distribution. However, the retrieved $\sigma_{\text {ext }}$ profile by using a constant LR profile method behaves differently and decreases at a rate of $-152.87\left(\mathrm{M} \mathrm{m}^{-1} \mathrm{~km}^{-1}\right)$. The structure of $\sigma_{\text {ext }}$ profiles is different by using the two different methods. Moreover, the retrieved $\sigma_{\text {ext }}$ from the RH profile of P90-95 at the top of the mixed layer is significantly deviated with a relative bias of $40 \%$.

Both Fig. 4a and c show that the retrieved $\sigma_{\text {ext }}$ is overestimated at the ground and underestimated at the top of the 

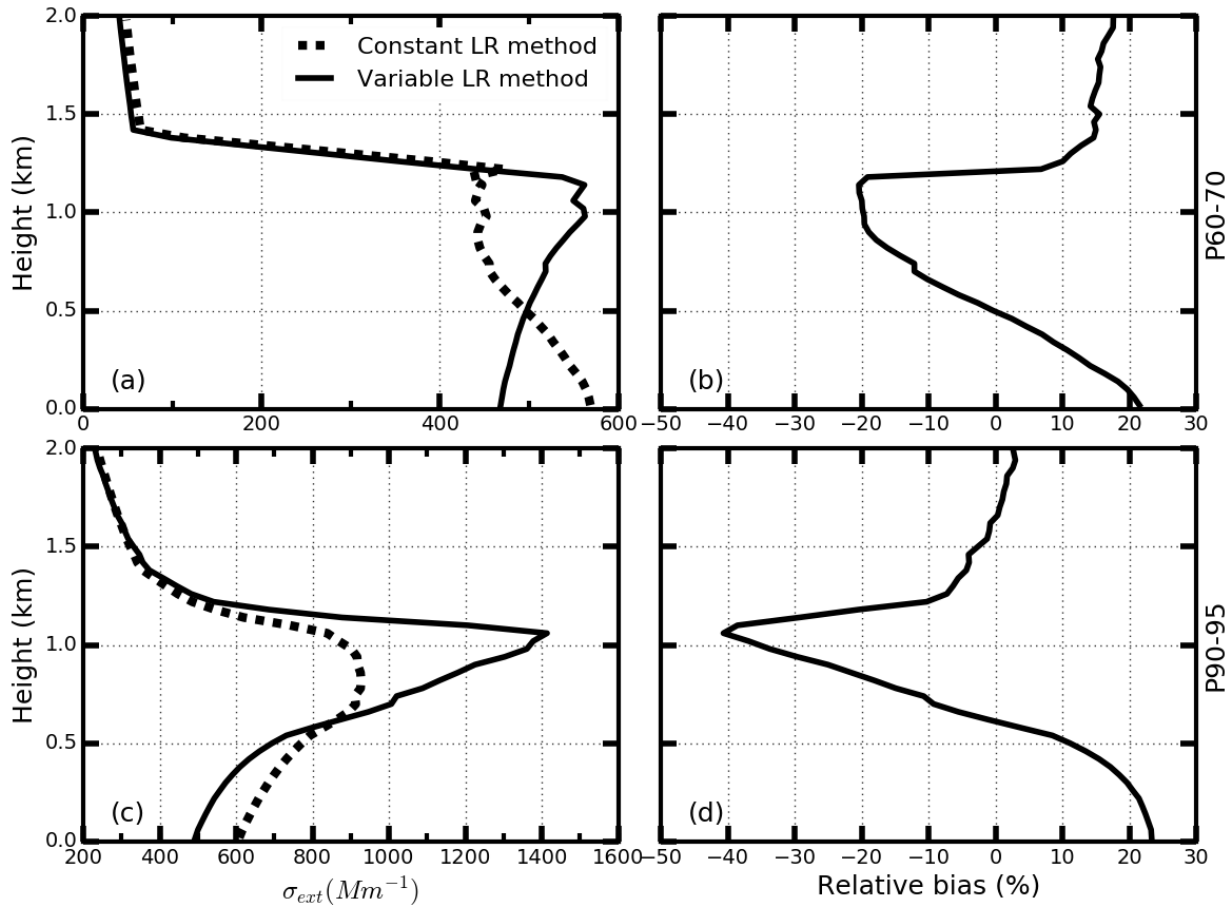

Figure 4. (a) Retrieved $\sigma_{\text {aero }}$ profiles using the constant LR profile method (dashed line) and the variable LR profile method (solid line) from simulated lidar signals. (b) The relative bias of the retrieved $\sigma_{\text {aero }}$ profile using two different methods. (c) and (d) are the same as (a), (b) respectively. The LR signals of panel (a) results from the P70-80 RH profile and LR signals of panel (b) results from the P90-95 RH profile.

mixed layer. From Fig. 3b, it can be concluded that the AODconstrained constant LR is larger than the calculated true LR at the ground and smaller at the top of the mixed layer. According to Eq. (3), signals of the elastic-backscatter lidar received at any height are proportional to the backscattering capability of the aerosols. When LR is larger, a larger fraction of the signals transfer forward and less is scattered back. In order to receive the same amount of signal, the backscattering coefficient should be larger and this can lead to the result of a larger $\sigma_{\mathrm{ext}}$ at that layer. Thus, the $\sigma_{\mathrm{ext}}$ tends to be biased higher than the given parameterized $\sigma_{\text {ext }}$ when the LR is larger, and vice versa. Overall, the profiles retrieved by using an AOD-constrained LR can lead to a positive bias at the ground and a negative bias at the top of mixed layer.

\subsubsection{Sensitivity study}

Simulations are conducted to study the characteristics of the retrieved $\sigma_{\text {ext }}$ profile bias between using the constant columnrelated LR profile and the variable LR profile. Different kinds of aerosol PNSD, AOD, aerosol hygroscopicity and RH profiles are used. Aerosol PNSD data come from the Hachi Campaign field measurements. The sensitivity of the bias in aerosol hygroscopicity is evaluated by changing the sizeresolved $\kappa$ value. Aerosols are defined to have high hygroscopicity when the aerosol size-resolved $\kappa$ value is one SD above the mean of the size-resolved $\kappa$ value. They are de- fined as low hygroscopicity if the size-resolved $\kappa$ value is one SD below mean of the size-resolved $\kappa$ value. Four different kinds of $\mathrm{RH}$ profiles are also used in this sensitivity study. As discussed in Sect. 3.2.1, a negative bias at the top of the mixed layer is accompanied by a positive bias at the ground and the largest bias happens at the top of the mixed layer. Thus, it is sufficient to focus on the relative bias at the top of the mixed layer.

Statistical characteristics of the relative bias at the top of the mixed layer are shown in Fig. 5. Different panels represent the results of different aerosol hygroscopicity. Figure 5a shows the results of low aerosol hygroscopicity, Fig. 5b shows results from mean aerosol hygroscopicity and high aerosol hygroscopicity of particles results in the properties shown in Fig. 5c. For each panel, the relationship between the relative bias and AOD are shown. Different colors in each panel show the results of different RH profiles. Filled colors represent the ranges of the relative biases at one SD by using different PNSDs.

Every panel shows that the relative bias clearly increases with the enhancement of RH in the surroundings. The relative bias has a mean value of less than $10 \%$ for the $\mathrm{RH}$ profile of P60-70. LR has little variation when the surrounding RH is low and the bias has a low value. For RH profiles of P70-80 and P80-90, the relative bias increases with $\mathrm{RH}$ and increases strongly up to $25 \%$ when the surrounding relative humidity is high. These behaviors of relative difference under differ- 


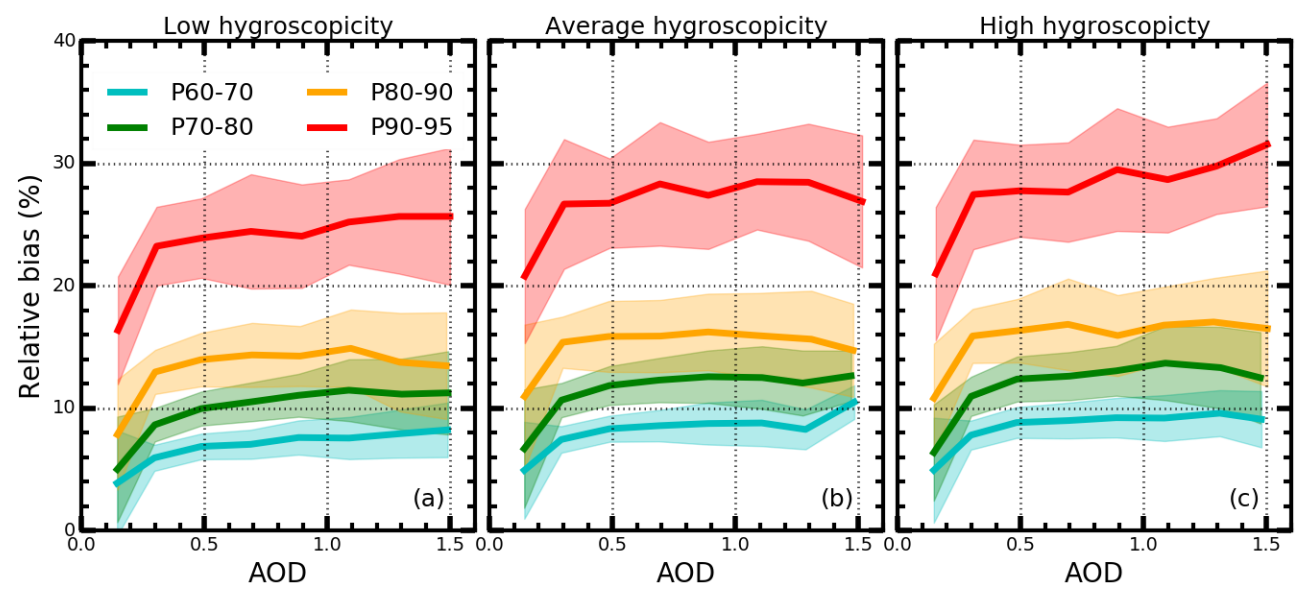

Figure 5. Relative biases of the retrieved $\sigma_{\text {ext }}$ under different AOD, PNSD, hygroscopicity and RH profile conditions. Different colors represent different RH profiles. Panel (a) is derived from low hygroscopicity, panel (b) results from the mean hygroscopicity and panel (c) is for high hygroscopicity.

ent RH conditions are consistent with the change of LR with RH.

Filled color ranges of relative bias at given AOD and RH profile result from the variation in aerosol PNSD. The LR enhancement factor can have different behaviors with different aerosol PNSDs according to Mie scattering theory. Changing the aerosol PNSD leads to a wider range of bias when the RH is higher. Figure 5 also shows that different PNSDs can change the relative bias by a mean value of $10 \%$ for different polluted conditions.

The relative bias increases with AOD value when the AOD is low, while it remains constant when the AOD is high. When AOD is low, the amount of scattered light by air molecules occupies a large fraction. Air molecules have a constant LR of $\frac{8}{3} \pi$ sr according to the Rayleigh scattering theory. The relative bias of the retrieved $\sigma_{\text {ext }}$ profile is relatively small when the AOD is low. When the AOD has a larger value, backscattered signals mainly depend on aerosol backscattering and the signals backscattered by air molecules are negligible. The relative bias mainly reflects the impacts of aerosol hygroscopicity. The mean relative bias increases from 26 to $32 \%$ at high RH conditions with the increase in aerosol hygroscopicity. Thus, aerosol hygroscopicity should be taken into account under high RH conditions.

To sum up, RH is one of the most important factors that influence the accuracy of retrieving the elastic-backscatter lidar data. Different PNSDs can also lead to a large variation in relative differences. The relative difference increases with the AOD when the AOD is low, but increases little when the AOD is high. Under the conditions of both high values of RH and AOD, the relative bias of retrieved data reaches a maximum due to the influence of aerosol hygroscopic growth.

\subsection{Evaluation of $L R$ enhancement factor parameterization}

Simulations are carried out to test the accuracy of the new methods of retrieving the $\sigma_{\text {ext }}$ profiles, which is proposed in Sect. 3.4.2. These simulations employ the elasticbackscattering lidar signals from Sect. 3.3, the RH profiles, the integrated AOD values of the parameterized $\sigma_{\text {ext }}$ profiles and the parameterization scheme of LR enhancement factor Eqs. (5) and (6). With this information, the $\sigma_{\text {ext }}$ profiles are retrieved by the method of Sect. 3.4.2. We then studied the relative biases between the parameterized $\sigma_{\text {ext }}$ profiles and the retrieved $\sigma_{\text {ext }}$ profiles by using the new method.

Different kinds of aerosol PNSD, AOD, aerosol hygroscopicity and RH profiles are used in the simulations. The relative biases are statistically studied and summarized. The values listed in Table 1 are the mean relative biases under different PNSD conditions. From Table 1, we can see that all of the relative biases are within the range of $13 \%$ for different PNSD, AOD, aerosol hygroscopicity and RH profiles. This indicates that the algorithm of using the mean LR enhancement factor parameterization scheme is feasible and can decrease the bias of the retrieved elastic-backscatter lidar data significantly.

\subsection{Retrieving the real-time measurement elastic-backscatter lidar signals}

MPL data and AERONET data were employed to validate the algorithm of retrieving the elastic-backscatter lidar data on the day of 5 July 2016. After quality control of data processing, elastic-backscatter lidar data were retrieved by using both the a constant LR profile method and the parameterized variable LR profile method. Details of retrieving the MPL signals and the auxiliary information are shown in Fig. S5. 

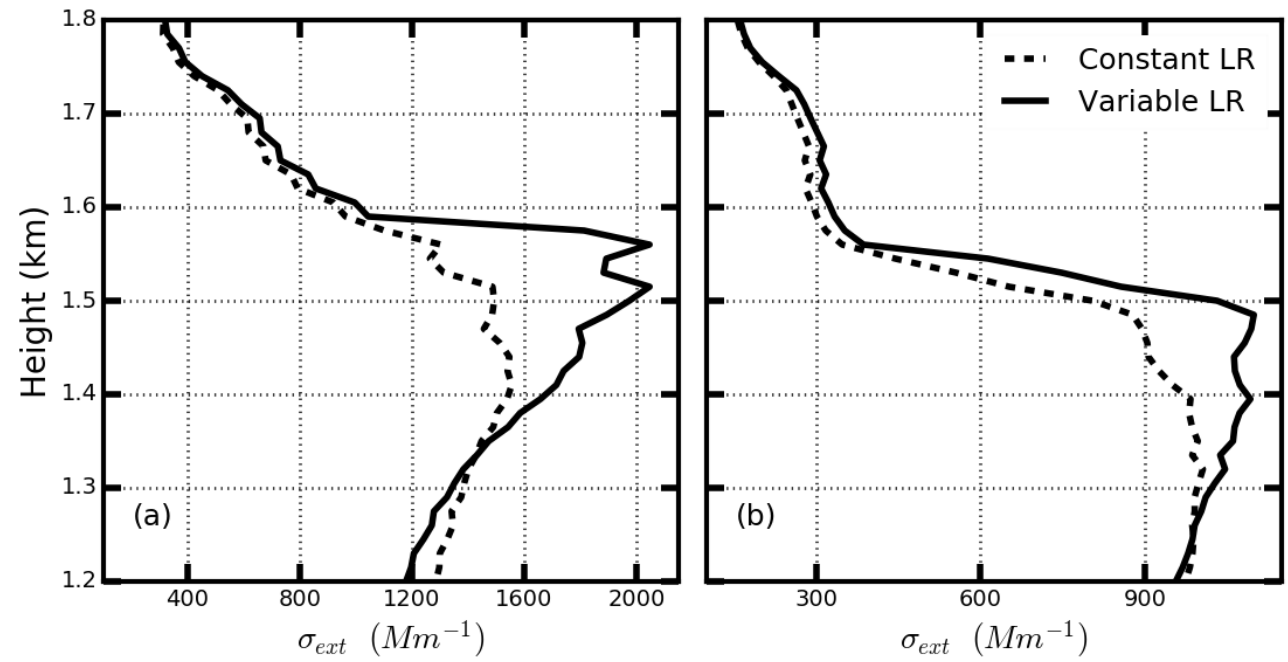

Figure 6. Retrieved $\sigma_{\text {ext }}$ profiles from field measurements from MPL signals at (a) 13:00 and (b) 14:30 LT on 5 July 2016. The dashed line represents the retrieved $\sigma_{\text {ext }}$ profiles using the constant LR profile method. The solid line represents the retrieved $\sigma_{\text {ext }}$ profiles using the variable LR profile method.

Table 1. Relative difference $(\%)$ between the $\sigma_{\text {ext }}$ profiles by using the proposed new method and the parameterized $\sigma_{\text {ext }}$ profiles under different AOD and RH profile conditions.

\begin{tabular}{rrrrrrrrrr}
\hline & \multicolumn{10}{c}{ AOD } \\
\cline { 3 - 10 } & & 0.2 & 0.4 & 0.6 & 0.8 & 1.0 & 1.2 & 1.4 & 1.6 \\
\hline \multirow{2}{*}{ RH profile } & P60-70 & 6 & 9 & 11 & 13 & 8 & 8 & 8 & 9 \\
& P70-80 & 7 & 7 & 9 & 12 & 7 & 6 & 7 & 8 \\
& P80-90 & 8 & 5 & 4 & 11 & 6 & 5 & 5 & 6 \\
& P90-95 & 9 & 6 & 6 & 9 & 13 & 7 & 7 & 9 \\
\hline
\end{tabular}

Figure 6 gives the retrieved $\sigma_{\text {ext }}$ profiles for two of local times: 13:00 (a) and 14:30 (b).

Figure 6a is a typical case of the retrieved $\sigma_{\text {ext }}$ profiles under high values of both RH and AOD. The retrieved $\sigma_{\text {ext }}$ profiles by using the constant LR profile method and variable LR profile method show almost the same properties as the simulations. The relative bias reaches a value of $39.3 \%$ at an altitude of $1.57 \mathrm{~km}$. These differences of retrieved $\sigma_{\mathrm{ext}}$ profiles may lead to a significant bias of estimating the mixed layer height and have a significant impact on the radiative energy distribution in the vertical direction. Figure $6 \mathrm{~b}$ shows the retrieved $\sigma_{\text {ext }}$ profiles of different structures from the same elastic-backscatter lidar data. The retrieved $\sigma_{\text {ext }}$ by using the variable LR profile method increases with height within the mixed layer. However, the retrieved $\sigma_{\text {ext }}$ by using the constant LR profile decreases slightly with height within the mixed layer.

\section{Conclusions}

The influence of aerosol hygroscopic growth on LR is evaluated by using Mie scattering theory. Datasets used as input to
Mie theory model come from the Hachi Campaign field measurements and these datasets can be used as a good representation of the continental aerosols. Results show that LR in the NCP mainly ranges from 30 to $90 \mathrm{sr}$, which is consistent with literature values of continental aerosols. LR could be enhanced significantly under high RH conditions, with a mean factor of 2.2 at $92 \% \mathrm{RH}$.

RH in the mixed layer in the NCP is frequently observed to be higher than $90 \%$. Under these conditions, a large variation in LR in the vertical direction exists. This leads to a significant bias of the retrieved $\sigma_{\text {ext }}$ profile due to a constant LR profile currently used to retrieve the elastic-backscatter lidar signals. The relative bias of the retrieved $\sigma_{\text {ext }}$ profiles between the constant LR profile method and the variable LR profile method can reach up to $40 \%$ under high $\mathrm{RH}$ conditions.

Sensitivity studies were carried out to test the bias of retrieved $\sigma_{\text {ext }}$ profiles. The bias increased linearly with RH at low RH but increased strongly at high RH. Different PNSDs can lead to $10 \%$ SD of the bias. Maximum bias happens under the conditions of both high AOD and RH that frequently happen in the NCP. The influence of aerosol hygroscopic 
growth on LR should be taken into consideration when retrieving the elastic-backscatter lidar data in the NCP.

A new algorithm accounting for the aerosol hygroscopic growth is proposed to retrieve the elastic-backscatter lidar data. A scheme of LR enhancement factor parameterization is introduced in this algorithm. The bias of retrieved $\sigma_{\text {ext }}$ profiles by using this algorithm can be constrained within $13 \%$. Real-time measurement of MPL data is employed to validate the algorithm and the results show good consistency with the simulations.

This research will advance our understanding of the influence of aerosol hygroscopic growth on LR and help to improve the retrieval of $\sigma_{\text {ext }}$ profiles from elastic-backscatter lidar signals.

Data availability. The data used are listed in the references and a repository at http://pan.baidu.com/s/1mioUlL2.

\section{The Supplement related to this article is available online at https://doi.org/10.5194/acp-17-12133-2017- supplement.}

Competing interests. The authors declare that they have no conflict of interest.

Acknowledgements. This work is supported by the National Natural Science Foundation of China (41590872, 41375134).

Edited by: Geraint Vaughan

Reviewed by: two anonymous referees

\section{References}

Ackermann, J.: The extinction-to-backscatter ratio of tropospheric aerosol: a numerical study, J. Atmos. Ocean. Tech., 15, 10431050, 1998.

Anderson, T. L. and Anderson, T. L.: Variability of aerosol optical properties derived from in situ aircraft measurements during ACE-Asia, J. Geophys. Res., 108, 15-19, 2003.

Anderson, T. L., Masonis, S. J., Covert, D. S., Charlson, R. J., and Rood, M. J.: In situ measurement of the aerosol extinction-tobackscatter ratio at a polluted continental site, J. Geophys. Res.Atmos., 105, 26907-26915, 2000.

Andreae, M. O. and Crutzen, P. J.: Atmospheric aerosols: biogeochemical sources and role in atmospheric chemistry, Science, 276, 1052-1058, 1997.

Ansmann, A., Wagner, F., Althausen, D., Müller, D., Herber, A., and Wandinger, U.: European pollution outbreaks during ACE 2: Lofted aerosol plumes observed with Raman lidar at the Portuguese coast, J. Geophys. Res.-Atmos., 106, 20725-20733, 2001.
Ansmann, A., Wagner, F., Müller, D., Althausen, D., Herber, A., von Hoyningen-Huene, W., and Wandinger, U.: European pollution outbreaks during ACE 2: optical particle properties inferred from multiwavelength lidar and star-Sun photometry, J. Geophys. Res.-Atmos., 107, 8-14, 2002.

Bian, J., Chen, H., ouml, mel, H., and Duan, Y.: Intercomparison of humidity and temperature sensors: GTS1, Vaisala RS80, and CFH, Adv. Atmos. Sci., 28, 139-146, 2011.

Birmili, W., Stratmann, F., and Wiedensohler, A.: Design of a DMA-based size spectrometer for a large particle size range and stable operation, J. Aerosol Sci., 30, 549-553, https://doi.org/10.1016/s0021-8502(98)00047-0, 1999.

Bohren, C. F. and Huffman, D. R.: Absorption and Scattering by an Arbitrary Particle, in: Absorption and Scattering of Light by Small Particles, Wiley-VCH Verlag GmbH, 57-81, 2007.

Chaikovsky, A., Dubovik, O., Holben, B., Bril, A., Goloub, P., Tanré, D., Pappalardo, G., Wandinger, U., Chaikovskaya, L., Denisov, S., Grudo, J., Lopatin, A., Karol, Y., Lapyonok, T., Amiridis, V., Ansmann, A., Apituley, A., Allados-Arboledas, L., Binietoglou, I., Boselli, A., D’Amico, G., Freudenthaler, V., Giles, D., Granados-Muñoz, M. J., Kokkalis, P., Nicolae, D., Oshchepkov, S., Papayannis, A., Perrone, M. R., Pietruczuk, A., Rocadenbosch, F., Sicard, M., Slutsker, I., Talianu, C., De Tomasi, F., Tsekeri, A., Wagner, J., and Wang, X.: Lidar-Radiometer Inversion Code (LIRIC) for the retrieval of vertical aerosol properties from combined lidar/radiometer data: development and distribution in EARLINET, Atmos. Meas. Tech., 9, 1181-1205, https://doi.org/10.5194/amt-9-1181-2016, 2016.

Chen, J., Zhao, C. S., Ma, N., Liu, P. F., Göbel, T., Hallbauer, E., Deng, Z. Z., Ran, L., Xu, W. Y., Liang, Z., Liu, H. J., Yan, P., Zhou, X. J., and Wiedensohler, A.: A parameterization of low visibilities for hazy days in the North China Plain, Atmos. Chem. Phys., 12, 4935-4950, https://doi.org/10.5194/acp12-4935-2012, 2012.

Chen, J., Zhao, C. S., Ma, N., and Yan, P.: Aerosol hygroscopicity parameter derived from the light scattering enhancement factor measurements in the North China Plain, Atmos. Chem. Phys., 14, 8105-8118, https://doi.org/10.5194/acp-14-8105-2014, 2014.

Fernald, F. G.: Analysis of atmospheric lidar observations: some comments, Appl. Optics, 23, 652-653, 1984.

Fernald, F. G., Herman, B. M., and Reagan, J. A.: Determination of aerosol height distributions by lidar, J. Appl. Meteorol., 11, 482-489, 1972.

Ferrare, R. A., Melfi, S. H., Whiteman, D. N., Evans, K. D., Poellot, M., and Kaufman, Y. J.: Raman lidar measurements of aerosol extinction and backscattering: 2. derivation of aerosol real refractive index, single-scattering albedo, and humidification factor using Raman lidar and aircraft size distribution measurements, J. Geophys. Res.-Atmos., 103, 19673-19689, 1998.

Ferrare, R. A., Turner, D. D., Brasseur, L. H., Feltz, W. F., Dubovik, O., and Tooman, T. P.: Raman lidar measurements of the aerosol extinction-to-backscatter ratio over the Southern Great Plains, J. Geophys. Res.-Atmos., 106, 20333-20347, 2001.

Ferrero, L., Perrone, M. G., Petraccone, S., Sangiorgi, G., Ferrini, B. S., Lo Porto, C., Lazzati, Z., Cocchi, D., Bruno, F., Greco, F., Riccio, A., and Bolzacchini, E.: Vertically-resolved particle size distribution within and above the mixing layer over the Milan metropolitan area, Atmos. Chem. Phys., 10, 3915-3932, https://doi.org/10.5194/acp-10-3915-2010, 2010. 
Ferrero, L., Mocnik, G., Ferrini, B. S., Perrone, M. G., Sangiorgi, G., and Bolzacchini, E.: Vertical profiles of aerosol absorption coefficient from micro-Aethalometer data and Mie calculation over Milan, Sci. Total Environ., 409, 2824-2837, 2011.

Gasteiger, J., Groß, S., Sauer, D., Haarig, M., Ansmann, A., and Weinzierl, B.: Particle settling and vertical mixing in the Saharan Air Layer as seen from an integrated model, lidar, and in situ perspective, Atmos. Chem. Phys., 17, 297-311, https://doi.org/10.5194/acp-17-297-2017, 2017.

He, Q. S., Li, C. C., Mao, J. T., Lau, A. K. H., and Li, P. R.: A study on the aerosol extinction-to-backscatter ratio with combination of micro-pulse LIDAR and MODIS over Hong Kong, Atmos. Chem. Phys., 6, 3243-3256, https://doi.org/10.5194/acp-6-32432006, 2006.

Klett, J. D.: Stable analytical inversion solution for processing lidar returns, Appl. Optics, 20, 211-220, 1981.

Klett, J. D.: Lidar inversion with variable backscatter/extinction ratios, Appl. Optics, 24, 1638-1643, 1985.

Kuang, Y., Zhao, C. S., Tao, J. C., and Ma, N.: Diurnal variations of aerosol optical properties in the North China Plain and their influences on the estimates of direct aerosol radiative effect, Atmos. Chem. Phys., 15, 5761-5772, https://doi.org/10.5194/acp15-5761-2015, 2015.

Kuang, Y., Zhao, C. S., Tao, J. C., Bian, Y. X., and Ma, N.: Impact of aerosol hygroscopic growth on the direct aerosol radiative effect in summer on North China Plain, Atmos. Environ., 147, 224233, 2016.

Liu, H. J., Zhao, C. S., Nekat, B., Ma, N., Wiedensohler, A., van Pinxteren, D., Spindler, G., Müller, K., and Herrmann, H.: Aerosol hygroscopicity derived from size-segregated chemical composition and its parameterization in the North China Plain, Atmos. Chem. Phys., 14, 2525-2539, https://doi.org/10.5194/acp-14-2525-2014, 2014.

Liu, P., Zhao, C., Zhang, Q., Deng, Z., Huang, M., Xincheng, M. A., and Tie, X.: Aircraft study of aerosol vertical distributions over Beijing and their optical properties, Tellus B, 61, 756-767, 2009.

Liu, P. F., Zhao, C. S., Göbel, T., Hallbauer, E., Nowak, A., Ran, L., Xu, W. Y., Deng, Z. Z., Ma, N., Mildenberger, K., Henning, S., Stratmann, F., and Wiedensohler, A.: Hygroscopic properties of aerosol particles at high relative humidity and their diurnal variations in the North China Plain, Atmos. Chem. Phys., 11, 3479-3494, https://doi.org/10.5194/acp-11-3479-2011, 2011.

Ma, N., Zhao, C. S., Nowak, A., Müller, T., Pfeifer, S., Cheng, Y. F., Deng, Z. Z., Liu, P. F., Xu, W. Y., Ran, L., Yan, P., Göbel, T., Hallbauer, E., Mildenberger, K., Henning, S., Yu, J., Chen, L. L., Zhou, X. J., Stratmann, F., and Wiedensohler, A.: Aerosol optical properties in the North China Plain during HaChi campaign: an in-situ optical closure study, Atmos. Chem. Phys., 11, 5959-5973, https://doi.org/10.5194/acp-11-5959-2011, 2011.

Ma, N., Zhao, C. S., Müller, T., Cheng, Y. F., Liu, P. F., Deng, Z. Z., Xu, W. Y., Ran, L., Nekat, B., van Pinxteren, D., Gnauk, T., Müller, K., Herrmann, H., Yan, P., Zhou, X. J., and Wiedensohler, A.: A new method to determine the mixing state of light absorbing carbonaceous using the measured aerosol optical properties and number size distributions, Atmos. Chem. Phys., 12, 23812397, https://doi.org/10.5194/acp-12-2381-2012, 2012.

Pappalardo, G., Amodeo, A., Mona, L., Pandolfi, M., Pergola, N., and Cuomo, V.: Raman lidar observations of aerosol emitted dur- ing the 2002 Etna eruption, Geophys. Res. Lett., 31, 179-211, 2004a.

Pappalardo, G., Amodeo, A., Pandolfi, M., Wandinger, U., Ansmann, A., Bösenberg, J., Matthias, V., Amiridis, V., De Tomasi, F., Frioud, M., Iarlori, M., Komguem, L., Papayannis, A., Rocadenbosch, F., and Wang, X.: Aerosol lidar intercomparison in the framework of the EARLINET project, 3. Ramanlidar algorithm for aerosol extinction, backscatter, and lidar ratio, Appl. Optics, 43, 5370-5385, 2004b.

Petters, M. D. and Kreidenweis, S. M.: A single parameter representation of hygroscopic growth and cloud condensation nucleus activity, Atmos. Chem. Phys., 7, 1961-1971, https://doi.org/10.5194/acp-7-1961-2007, 2007.

Pietruczuk, A. and Podgórski, J.: The lidar ratio derived from sun-photometer measurements at Belsk geophysical observatory, Acta Geophys., 57, 476-493, doi10.2478/s11600-009-0006-9, 2009.

Pietruczuk, A. and Podgorski, J.: The lidar ratio derived from sun-photometer measurements at Belsk geophysical observatory, Acta Geophys., 57, 476-493, 2009.

Ran, L., Deng, Z., Xu, X., Yan, P., Lin, W., Wang, Y., Tian, P., Wang, P., Pan, W., and Lu, D.: Vertical profiles of black carbon measured by a micro-aethalometer in summer in the North China Plain, Atmos. Chem. Phys., 16, 10441-10454, https://doi.org/10.5194/acp-16-10441-2016, 2016.

Rosati, B., Herrmann, E., Bucci, S., Fierli, F., Cairo, F., Gysel, M., Tillmann, R., Größ, J., Gobbi, G. P., Di Liberto, L., Di Donfrancesco, G., Wiedensohler, A., Weingartner, E., Virtanen, A., Mentel, T. F., and Baltensperger, U.: Studying the vertical aerosol extinction coefficient by comparing in situ airborne data and elastic backscatter lidar, Atmos. Chem. Phys., 16, 4539-4554, https://doi.org/10.5194/acp-16-4539-2016, 2016.

She, C. Y., Alvarez, R. J., Caldwell, L. M., and Krueger, D. A.: High-spectral-resolution Rayleigh-Mie lidar measurement ofaerosol and atmospheric profiles, Opt. Lett., 17, 541-543, 1992.

Shipley, S. T., Tracy, D. H., Eloranta, E. W., Trauger, J. T., Sroga, J. T., Roesler, F. L., and Weinman, J. A.: High spectral resolution lidar to measure optical scattering properties of atmospheric aerosols, 1: Theory and instrumentation, Appl. Optics, 22, 3716-3724, 1983.

Sroga, J. T., Eloranta, E. W., Shipley, S. T., Roesler, F. L., and Tryon, P. J.: High spectral resolution lidar to measure optical scattering properties of atmospheric aerosols, 2: Calibration and data analysis, Appl. Optics, 22, 3725-3732, 1983.

Sušnik, A., Holder, H., and Eichinger, W.: A minimum variance method for lidar signal inversion, J. Atmos. Ocean. Tech., 31, 468-473, 2014.

Wex, H., Neususs, C., Wendisch, M., Stratmann, F., Koziar, C., Keil, A., Wiedensohler, A., and Ebert, M.: Particle scattering, backscattering, and absorption coefficients: an in situ closure and sensitivity study, J. Geophys. Res.-Atmos., 107, 8122, https://doi.org/10.1029/2000JD000234, 2002.

Xu, W. Y., Zhao, C. S., Ran, L., Deng, Z. Z., Liu, P. F., Ma, N., Lin, W. L., Xu, X. B., Yan, P., He, X., Yu, J., Liang, W. D., and Chen, L. L.: Characteristics of pollutants and their correlation to meteorological conditions at a suburban site in the North China Plain, Atmos. Chem. Phys., 11, 4353-4369, https://doi.org/10.5194/acp-11-4353-2011, 2011. 